EM

\title{
O PERFIL DOS SUJEITOS SOCIAIS QUE COMPÕEM AS REDES DE RECICLAGEM BRASILEIRA
}

\section{THE PROFILE OF THE SOCIAL SUBJECTS THAT MAKE UP THE BRAZILIAN RECYCLING NETWORKS}

\author{
Uilmer Rodrigues Xavier da CRUZ ${ }^{1}$
}

\begin{abstract}
Resumo: A construção da identidade é fruto das relações entre os indivíduos e os espaços, compondo uma dinâmica que está sempre em constante construção. Assim, os sujeitos sociais possuem características que resultam de suas relações com os espaços e da soma das múltiplas escalas imbricadas e estabelecidas em múltiplos relacionamentos e de diversas maneiras. Portanto, o propósito deste trabalho é refletir para se obter uma compreensão geográfica sobre os sujeitos sociais, suas relações e as redes de produção relacionadas à atividade de reciclagem brasileira. Sendo assim, desvelou-se as relações de poder que existem na atividade de reciclagem e da catação, observando o espaço e a construção da identidade dos sujeitos que compõem essa rede. Além disso, traçou-se um perfil quantitativamente desses indivíduos de acordo com IBGE/PNAD, fazendo um estudo comparativo na escala nacional a partir dos sujeitos catadores. Por fim, afirma-se que a discussão deste artigo provocou uma análise nas relações de trabalho e exploração dos sujeitos que trabalham na reciclagem de resíduos recicláveis, fomentando uma melhor compreensão da organização desigual do espaço.
\end{abstract}

Palavras-Chave: Perfil dos catadores brasileiros; Produção das identidades; Catação e relações de poder.

\begin{abstract}
The construction of identity is the result of the relationships between individuals and spaces, composing a dynamic that is always in constant construction. Thus, social subjects have characteristics that result from their relationships with spaces and from the sum of multiple nested and established scales in multiple relationships and in different ways. Therefore, the purpose of this work is to reflect in order to obtain a geographical understanding of social subjects, their relations and the production networks related to the Brazilian recycling activity. Thus, the power relations that exist in the recycling and collection activity were unveiled, observing the space and the construction of the identity of the subjects that make up this network. In addition, a profile was quantitatively required according to the IBGE / PNAD, making a comparative study on a national scale from the collectors. Finally, it is stated that the discussion of this article provoked an analysis of the work and exploitation relationships of the subjects who work in recycling recyclable waste, promoting a better understanding of the uneven organization of space.
\end{abstract}

\footnotetext{
${ }^{1}$ Doutorando em Geografia pela Universidade Federal de Minas Gerais (UFMG), Bolsista de doutorado da Fundação de Amparo à Pesquisa do Estado de Minas Gerais (FAPEMIG) (2020). Mestre em Geografia pela Universidade do Estado do Rio de Janeiro (UERJ) (2019), Graduação em Geografia - Ênfase em Sistemas de Informações Geográficas pela Pontifícia Universidade Católica de Minas Gerais (PUC-MG) (2008). E-mail: uilmer@ufmg.brou uilmer_rodrigues@hotmail.com

Palavras iniciais: $\mathrm{O}$ perfil dos sujeitos sociais que compõem as redes de reciclagem brasileira. $\mathrm{O}$ presente artigo faz parte da pesquisa "As redes de produção da reciclagem no estado do Rio de Janeiro: circuitos espaciais e os desafios dos catadores de materiais recicláveis." concluída no curso de Mestrado em Geografia - Programa de Mestrado em Geografia, da Faculdade de Formação de Professores da UERJ, na linha de pesquisa - Geografia e Relações de Poder.
} 
EM

QUESTÃO

V.13 N. $03 \bullet 2020$

pág. 98-114

Keywords: Profile of waste pickers; Production of identities; Gathering and power relations.

\section{Introdução}

Conceitualmente, pode-se estabelecer uma compreensão acerca de espaço geográfico enquanto um construto social. Como afirma Massey (2008), o espaço constitui-se a partir de uma tríade que, define a autora, é interdependente em seus pontos. Deste modo, o espaço é produto das interrelações - que se estabelecem socialmente, através dos sujeitos -, é esfera de multiplicidades, as quais compõem as relações sociais de maneira identitária e está em constante construção, ou seja, é dinâmico, está sempre em devir de algo.

Compreendendo desta maneira, é importante destacar que, sem as relações sociais, o espaço não se constitui pré-discursivamente e, da mesma maneira, as relações não se estabelecem sem a existência do espaço, sendo esta uma compreensão estabelecida em diálogo com Corrêa (2000). Essa afirmação corresponde a uma compreensão de que o espaço e as relações sociais são co-constituintes, ou seja, se estabelecem a partir de uma interdependência. Isso significa que os sujeitos sociais terão em suas trajetórias cotidianas nuances resultantes de espacialidades específicas, bem como da soma de múltiplas escalas intrínsecas às relações estabelecidas de diversas maneiras.

É neste sentido que o propósito deste momento de reflexão é demarcado, uma compreensão geográfica acerca de sujeitos sociais e redes (conceito-chave da disciplina científica em questão) e, mais especificamente, sujeitos relacionados à rede de reciclagem brasileira, em como compõem suas relações.

Sendo assim, não se pode deixar de lembrar que é o próprio sistema capitalista de produção que demanda que existam esses sujeitos sociais que estão envolvidos na prática da catação e da reciclagem, sujeitos que representam a força de trabalho de uma população explorada e marginalizada que sofre com os baixos rendimentos, enquanto aquele que explora lucra com o fruto do seu trabalho.

O trabalho desses sujeitos sociais, catadores de materiais recicláveis, é o elo mais frágil na base da hierarquia, mesmo com toda a sua importância social, e está intimamente ligado a luta pela sobrevivência, uma vez que a pouca qualificação e a ausência de outras alternativas de trabalho formal, faz com que o acesso dessa população a determinadas esferas sociais seja limitado.

Nesse sentido, a discussão deste artigo se divide em três partes. A primeira, "Catação e as relações de poder", procura refletir sobre como a prática da coleta seletiva, e toda sua rede desigual, é retroalimentada pela lógica do sistema capitalista, favorecendo sempre a apenas uma parcela da sociedade. Além disso, observa-se a reciclagem enquanto rede de produção e não apenas de relações sociais, composta por diversos sujeitos que exercem funções diferenciadas na produção dos materiais reciclados. Considerando, contudo, que, por mais que o poder parta de diferentes pontos da rede, e de diferentes sujeitos, haverá circulação desigual de capital, informação e poder entre os participantes, sendo os mesmos ordenados hierarquicamente, mediante a posição social em que se situam.

A segunda parte, "A produção das identidades e seus quebra-cabeças", procura refletir sobre a construção da identidade das pessoas que vivenciam o cotidiano de maneira espacial, demonstrando que, assim como o espaço, a identidade é um construto social, e que ambos conceitos estão imbricados influenciando no processo de construção e estratificação social. $\mathrm{O}$ que pode significar a posição marginal de alguns sujeitos em determinados espaços, de acordo com as interrelações desses sujeitos ao longo de suas trajetórias.

Então, a terceira parte "Catadores de materiais recicláveis no estado brasileiro" busca traçar um perfil, com base em dados quantitativos e qualitativos, dos catadores de materiais 
EM

recicláveis, que são responsáveis pela coleta seletiva de resíduos sólidos recicláveis, triagem, classificação, processamento e comercialização dos resíduos, exercendo papel fundamental no cenário da Rede de Reciclagem do Brasil. Procura compreender que mesmo em condições precárias de trabalho, a atividade continua acontecendo, tanto nas ruas, quanto nas cooperativas, observando e analisando dados sociais importantes como as taxas de analfabetismo dessa população, as relações de gênero que existem entre os trabalhadores dessa rede e suas posições de marginalização, a relação que existe no espaço entre as moradias desses sujeitos e os pontos de coleta ou locais de trabalho, dentre outros aspectos fundamentais para o conhecimento do perfil do catador da rede de reciclagem brasileira.

Portanto, nossa proposta reside em compreender as relações de poder que existem na atividade de reciclagem e catação, observando o espaço e a construção da identidade dos sujeitos que compõem a rede de produção da reciclagem em questão e traçando um perfil mais detalhado quantitativamente dos mesmos.

\section{Metodologia: a rota, com seus atalhos e contornos de uma pesquisa que nasce e quer chegar ao seu destino}

Esta seção pretende apresentar o caminho metodológico para a realização do artigo sobre o perfil dos catadores das redes de produção da reciclagem no estado brasileiro, visando compreender a atuação dos sujeitos envolvidos, e, também, os conflitos e barreiras existentes na produção da reciclagem, seja na implementação de políticas públicas ou nos limites das ações coletivas. Além disso, pretendemos analisar a situação socioeconômica dos catadores, a partir dos dados coletados pelo PANGEA (2018). A abordagem proposta abarca um espectro amplo de processos, ações e relações sociais e espaciais, que exigirá diferentes procedimentos metodológicos, qualitativos e quantitativos.

Entende-se que a "Metodologia Científica é muito mais do que algumas regras de como fazer a pesquisa. Ela auxilia a refletir e propicia um 'novo' olhar sobre o mundo: um olhar científico, curioso, indagador e criativo" (GOLDENBERG, 2004, p. 11). Assim, compreende-se a metodologia não apenas como um meio ferramental para ser utilizado com o fim da observação dos fenômenos sociais, mas também um mecanismo de percepção da realidade que mediará o processo de apreensão do conhecimento, a fim de alcançar novos olhares sobre o objeto escolhido para a investigação, que pode ser qualitativa ou quantitativa. Minayo (2001, p. 21) afirma que "a pesquisa qualitativa possui um nível da realidade que não pode ser quantificado, mensurado em toda a sua complexidade". Já para Ramires e Pessôa:

A pesquisa qualitativa tem como identidade o reconhecimento da existência de uma relação dinâmica entre o mundo real e o sujeito, de uma interdependência viva entre sujeito e objeto e de uma postura interpretativa, constituindo-se como um campo de atividade que possui conflitos e tensões internas (2013, p. 25).

Sendo assim, para compreensão dos conflitos e disputas que envolvem as redes de produção da reciclagem, precisaremos, em determinado momento, utilizar de recursos metodológicos de base qualitativa. Deste modo, permitirá uma aproximação mais detalhada e particular da realidade pesquisada. No modo qualitativo de pesquisa, “... a preocupação do pesquisador não é com a representatividade numérica do grupo pesquisado, mas com o aprofundamento da compreensão de um grupo social, de uma organização, de uma instituição, de uma trajetória etc." (GOLDENBERG, 2004, p. 12). A métrica quantitativa, então, é 
EM

substituída pela intensidade, numa imersão subjetiva, em que a observação é cuidadosa, por meio de entrevistas, atuação participativa e análises de diferentes fontes documentais.

Por compreender que a pesquisa deva contemplar os enlaces econômicos, políticos, históricos e sociais que constroem as relações sociais, considerando a complexidade da realidade espacial estabelecida neste trabalho, utilizamos tanto dados quantitativos, provindo das bases do PANGEA, para analisar a relação capital-trabalho e a condição socioeconômica dos catadores, como dados qualitativos, oriundos da análise de documentos e, principalmente, da experiência vivida pelo pesquisador no campo da reciclagem. Neste, busquei compreender a organização espacial das redes de produção da reciclagem e os avanços e entraves que caracterizam as políticas públicas do setor no estado brasileiro, a partir dos catadores.

A fim de apresentar o catador e suas condições de vida, recorreremos a Santos (1995), que nos diz que se a desigualdade é um fenômeno socioeconômico, a exclusão é, principalmente, um fenômeno cultural e social, um fenômeno de civilização. E, assim, a cultura se fortalece e se legitima por um discurso histórico supostamente verídico e que tem por objetivo não só ditar o que precisa ser seguido, mas também rejeitar tudo aquilo que não se enquadra. Refere-se a um processo histórico pelo qual uma cultura, através de um discurso de verdade, gera o interdito e o rejeita. Aos catadores, então, são empurrados para a condição de marginalidade na sociedade, em que o seu lugar é visto como subalterno e invisível, ainda que ocupe uma função de suma importância na rede de produção da reciclagem. Buscaremos, então, levantar as condições socioeconômicas dos catadores, em que prevalece seu caráter de exclusão e invisibilidade social.

Pretendemos, assim, partir do fenômeno em si e não da sua representação, indo além das aparências e superando as primeiras impressões ofertadas pelas redes de produção e pelas políticas públicas estabelecidas para o cenário histórico e geográfico analisado, na tentativa da reconstrução da realidade no plano abstrato e no retorno ao plano concreto.

O trabalho de pesquisa, propriamente dito, a observação no campo, corresponde à grande escala e, neste nível, é somente uma parte dos fenômenos que pode ser convenientemente apreendido, os outros devem ser antevistos em escala menor e é preciso, para isto, utilizar representações que a pesquisa no terreno não pode fornecer. $O$ trabalho de campo, para não ser somente um empirismo, deve articular-se à formação teórica que é, ela também, indispensável. Saber pensar o espaço não é colocar somente os problemas no quadro local, é também articulá-los eficazmente aos fenômenos que se desenvolvem sobre extensões muito mais amplas. Não é menos verdade que a pesquisa, na medida em que ela corresponde à extração de um abstrato a partir de um concreto, pela pesquisa e pela observação de campo, dá uma grande importância ao nível de conceitualização em grande escala (evidentemente, a pesquisa pode também partir, sobretudo, das abstrações já elaboradas, a formação dos pesquisadores é então diferente e muito menos titubeante). (LACOSTE, 2006, p. 91).

Portanto, o compromisso assumido pela pesquisa, ao se propor problematizar e compreender as relações estabelecidas no cenário da reciclagem é contribuir para um olhar mais qualificado dos atores (governos, indústrias, comerciantes, cooperativas, etc.) envolvidos na rede de produção da reciclagem, na formulação e implementação de ações voltadas para toda a rede e os sujeitos que a praticam em seus cotidianos.

Dentre os documentos que foram analisados, destacamos o relatório desenvolvido pela Secretaria Estadual do Meio Ambiente - CRS/ Fundação Getúlio Vargas - FGV e pela ONG PANGEA - Centro de Estudos Socioambientais. Concomitantemente a PNAD e o CENSO são pesquisas de cunho domiciliar amostral e auto declaratória, a sua metodologia pode 
EM

subestimar as informações dos catadores. Muitos destes não possuem um domicílio fixo e, mesmo os que possuem, encontram-se em locais de difícil acesso, dificultando, assim, o trabalho dos recenseadores. Isto é corroborado pela literatura especializada, como nos afirmam Porto Gonçalves (2006) e, Bosi (2008), Burgos (2008), Rosado (2009) e Dagnino (2010), quando nos dizem que a maioria dos catadores moram nas periferias, na rua ou nos lixões.

\section{Revisão teórica - catação e as relações de poder}

A prática da reciclagem está diretamente ligada ao modo capitalista de produção. A produção massiva de bens de consumo, que alimenta a lógica de manutenção do capital constante (Harvey, 2011) e, por sua vez, o propósito de geração de lucros crescentes para os capitalistas está indissociada do descarte excessivo de resíduos sólidos.

Para a indústria da reciclagem, a principal justificativa para o processo de reciclagem de resíduos descartados provém da necessidade de se utilizar a mesma matéria-prima utilizada em produções anteriores de mercadorias, dada escassez de material relacionada à exploração constante dos recursos (naturais), seja no presente ou por projeções de consequências futuras.

A partir disso, soma-se a possibilidade de aferir lucros em um novo setor de acumulação, aproveitando-se do baixo custo da matéria prima proveniente da reciclagem de resíduos sólidos urbanos e da baixa remuneração de sua coleta. Ainda funciona como forma de legitimar uma rede de produção baseada nos "descartáveis", uma vez que passa a ser caracterizado como "ambientalmente correto", reduzindo oposição ou crítica social. Simultânea à necessidade das indústrias de reciclagem por maiores taxas de lucro, soma-se a exploração do trabalho de catadores, responsáveis pela coleta de resíduos sólidos urbanos, mas também a incorporação de novas tecnologias, que diminuem o custo de produção e circulação dos materiais recicláveis. Desta maneira, colabora-se ${ }^{2}$ para a manutenção do ciclo da mais-valia e, por sua vez, para a acumulação de capital.

O trabalho de catadores de materiais recicláveis está ligado à luta pela sobrevivência destes indivíduos. A ausência de alternativas de trabalho formal, por sua vez, impede-os do acesso a determinadas esferas sociais intrínsecas à sociedade de classes. Para além disso, sua prática laboral cotidiana pode ser interpretada como "ambientalista" - coleta seletiva de resíduos sólidos urbanos e a destinação correta destes resíduos, como destaca Rosado (2009).

Rosado (2009), em seu olhar acerca da realidade socialmente invisibilizada dos catadores, e, mais a fundo, catadoras de lixo, afirma que apesar da estratégia de sobrevivência dos sujeitos que se utilizam da catação como fonte de renda, tais sujeitos sofrem uma exposição exacerbada em seus cotidianos a um ciclo de exploração que os colocam em condição de marginais nas redes de relações sociais de que envolvem a reciclagem.

Segundo a autora: "Podemos definir as redes sociais como um sistema aberto em permanente construção, que se tecem e entretecem individual e coletivamente. " (ROSADO, 2009 , p. 34). A autora ainda afirma que a 'rede de reciclagem' constitui em uma esfera na qual trajetórias cotidianas se inter-relacionam:

\footnotetext{
${ }^{2}$ A ideia de colaborar para a manutenção do ciclo do mais-valia e para o acúmulo de capital não significa que a atividade de catação não se apresente como, além de força de trabalho que se converte aos interesses do capital, um ato de resistência de sujeitos marginais nas relações sociais que se instituem no sistema capitalista de produção e, por sua vez, nas cidades. Porém, é justificada pela ideia de que em toda relação social, há uma relação de poder e que, para haver relações de poder (sociais) também há opressão e resistência (entre diferentes sujeitos), como propõe Foucault (1995).
} 
EM

(...) pelas conexões entre as pessoas que ocupam posições no jogo do lixo, no qual os distintos atores interagem, tendo cada nó uma posição específica e interdependente das demais no complexo campo do lixo, vivenciando um conjunto de relações econômicas, sociais, políticas e culturais que dele emergem (ROSADO, 2009, p. 34).

A compreensão do conceito de redes que a autora assume para sua discussão parte da noção de que as redes são constituídas por relações de poder que, através da comunicação, trocam significados que se materializam nos enlaces produzidos pelos e entre os sujeitos, que, por sua vez, permitem a circulação destes significados, a partir das práticas espaciais materializadas no cotidiano. Tal relação entre rede e poder também é destacada por Raffestin que afirma que:

É conveniente, pois, decifrar as redes por meio de sua história e do território no qual estão instaladas, por meio dos modos de produção que permitiram a sua instalação e das técnicas que lhes deram forma. As redes são não somente a exibição do poder, mas são ainda feitas à imagem do poder (RAFFESTIN, 1993, p. 209).

Assim como Raffestin (1993), Rosado (2009) compreende a rede enquanto parte integrante de um território, espaço constituído por e a partir relações de poder (SOUZA, 1994). Deste modo, é compreensível que uma rede social de reciclagem, como trata Rosado (2009), seja constituída por relações de poder e, assim, também por conflitos, que partem de diferentes sujeitos que constituem a lógica da produção da reciclagem de resíduos.

Segundo Foucault (1995), o conceito de poder refere-se a um agrupado de práticas e ações que são correspondentes umas às outras. Para o autor, não se trata de um exercício unilateral de alguém sobre algo ou outro alguém, mas de um conjunto de ações que partem de diferentes polos. Ou seja, não ocorrem de maneira unidirecional e dependem da aceitação e/ou resistência dos diferentes sujeitos que constituem as relações sociais.

Como elucida Silva (2017) a respeito da necessidade de trazer à tona os discursos dos principais sujeitos da rede de reciclagem, por vezes tal relação de trabalho é tensionada a partir do empoderamento dos catadores. Lussari (2016) leva a uma compreensão um pouco além das cooperativas como importantes para o empoderamento dos trabalhadores relacionados à coleta seletiva. Porém, caminha no entendimento de que transformar a força de trabalho individual em coletiva colabora para o fortalecimento do discurso dos trabalhadores perante a rede de reciclagem. Conforme destaca o autor:

Ao discutir-se a emergência de uma cultura organizacional em uma cooperativa de recicladores de resíduos sólidos, cujos cooperados são oriundos de um estado de trabalho diferente do necessário, para se estabelecer na nova ocupação, há a necessidade de se entender todo o contexto histórico, social e político, de forma a estabelecer um lugar, um território e um espaço, em que se crie uma nova identidade do trabalhador (LUSSARI, 2016, p. 184).

Como nos demonstram não apenas Dagnino e Dagnino (2010), porém, presente na reflexão de outros autores, como Costa e Chaves (2012) e Bosi (2008), a organização dos catadores envolvidos na rede de produção da reciclagem de resíduos sólidos urbanos, através de cooperativas, insere-se no campo de lutas para a visibilidade dos trabalhadores da catação e direcionada ao fomento de políticas públicas que envolvam estes sujeitos. 
EM

Nossa proposta, todavia, reside em compreender a reciclagem enquanto uma rede de produção e não apenas de relações sociais, composta por diversos sujeitos que exercem funções diferenciadas na produção dos materiais reciclados. Considerando, contudo, que, por mais que o poder parta de diferentes pontos da rede e de diferentes sujeitos, haverá circulação desigual de capital, informação e poder entre os participantes, ordenando-os hierarquicamente.

Fato é que as redes de produção da reciclagem se realizam em diversas escalas geográficas (global, nacional, regional e urbana), nas quais a lógica capitalista da indústria de reciclagem se (re)produz e, destarte, tendo relação direta com a situação econômica, política e espacial dos sujeitos e atores que a constituem nas cidades (escala intra-urbana).

Assim, afirma Rosado (2009) que a posição de mediado e mediador na rede de reciclagem depende justamente da compreensão discursiva dos sujeitos que constituem tal rede, ou seja, da condição social na qual os sujeitos se inserem.

Não podemos partir do pressuposto que todos os agentes envolvidos (mediadores e mediados) possuem a mesma condição de entendimento, pois o mediador assume esse papel, justamente, pela dificuldade do mediado em relacionar-se com outros jogos de linguagem, ou seja, o mediador somente tem razão de existir na relação se for para cumprir este papel. (...) É mais interessante para o grupo social que o mediador atribua validade ao seu discurso (em diferentes meios) e que procure traduzi-lo no discurso do outro. Assim, na prática mediadora, pode-se perceber uma "violência simbólica" pela subjugação da cultura, do entendimento acerca do mundo, do próprio mediado (ROSADO, 2009, p. 110).

A posição da autora supracitada colabora na compreensão de que haverá, em uma rede de reciclagem, práticas e ações desiguais entre os sujeitos, mediante a posição social que os mesmos se situam. Os catadores de materiais recicláveis, em particular os catadores de ruas, constroem suas vivências na condição de sujeitos mediados em subordinação aos atravessadores, na ausência de cooperativas ou galpões de reciclagem de resíduos sólidos urbanos, ainda que nestas últimas contemplem outro tipo de relação de poder.

\section{A produção das identidades e seus quebra-cabeças}

Os sujeitos sociais ou, em outros termos, as pessoas que vivenciam o cotidiano de maneira espacial, constituem-se de maneira identitária. É importante destacar que, assim como o espaço, a identidade é um construto social - ou seja, assim como o conceito anteriormente abordado, não se estabelece de maneira pré-discursiva aos sujeitos. Segundo Bauman (2005), as identidades dos sujeitos seriam como um quebra-cabeças, sem manual de montagem e com peças faltantes, sendo então de complexa compreensão e sempre incompletas. Ainda, para o autor, a identidade é resultante de uma história em constante construção que não se coloca enquanto linear, respectiva à vida dos seres humanos (sociais), com mudanças ao longo de suas trajetórias, compreendendo marcadores como: raça, gênero, etnia, classe de renda, sexualidade, dentre outros. Ainda em Bauman (2005), é válido o destaque: 
EM

ainda se precisa construir a partir do zero ou escolher entre alternativas e então lutar por ela e protegê-la lutando ainda mais (BAUMAN, 2005, p. 21).

O autor ainda argumenta que o processo de identificação de um sujeito, ou seja, de sua constituição identitária, colabora para a estratificação social, destacando então os sujeitos com relação aos seus feixes identitários - identificando-os conforme estes feixes -, sendo tais feixes, muitas vezes, correspondentes a 'padrões' hegemônicos e outrora não, significando então a marginalidade de algumas pessoas em determinadas escalas espaciais.

Outro autor que estabelece uma discussão acerca do conceito de Identidade é Hall (2011).

Assim como para Bauman (2005), para Hall (2011) a identidade se mantém enquanto um produto social. Segundo o autor, as identidades não se estabelecem nunca de maneira fixa - assim como o espaço, destacado anteriormente -, sendo maleáveis e mutáveis, em suas palavras destaca que a identidade: "É definida historicamente, e não biologicamente. O sujeito assume identidades diferentes em diferentes momentos, identidades que não são unificadas ao redor de um 'eu' coerente" (HALL, 2011, p. 13).

É possível perceber a confluência na reflexão dos dois autores em relação ao conceito de identidade e a relação do conceito enquanto instituição de sujeitos sociais que, de modo discursivo, ou seja, através de suas relações sociais e espaciais, constroem suas identidades em movimentos de constantes mudanças e adaptações conforme a realidade em que se inserem. $\mathrm{O}$ modo pelo qual as pessoas se estabelecem enquanto sujeitos, ou seja, assumem posturas identitárias é, assim, um componente fundamental das relações espaciais.

A partir deste ponto, é válido o retorno para o apresentado anteriormente segundo Massey (2008) e Corrêa (2000), que destacam uma compreensão do conceito geográfico de espaço enquanto um construto social instituído a partir de interrelações dos sujeitos. O ponto culminante entre a autora e o autor supracitados e os dois autores que anteriormente dialoguei acerca do conceito de identidade, está na afirmação de que, geograficamente, os sujeitos enquanto seres sociais/identitários não podem ser vistos para além de uma escala espacial, ou seja, a existência destes sujeitos é espacial e, por sua vez, geográfica.

Quando se parte de uma perspectiva de espaço, como até agora defendida, ainda é necessário carregar uma definição de que, se o espaço é social, assim como são os sujeitos, é também composto de histórias que se constituem de maneira não linear, porém carregadas de significados reafirmados em detrimento de outros negados pelos sujeitos que o instituem.

Nesta perspectiva, Pollack (1992) argumenta acerca da memória identitária/social dos indivíduos/sujeitos enquanto componentes socioculturais destes. Para o autor, a identidade de um sujeito pode ser considerada enquanto uma visualização de cada um sobre si mesmos e para outrem. Para além, apesar de constituir-se enquanto uma apreensão do indivíduo, também se estabelece de maneira externa ao mesmo, ou seja, como Pollack (1992) afirma, depende da aprovação do círculo social em que se insere. Nas palavras do autor: "A construção da identidade é um fenômeno que se produz em referência aos outros, em referência aos critérios de aceitabilidade, de admissibilidade, de credibilidade, e que se faz por meio da negociação direta com outros. " (POLLACK, 1992, p. 204)

Ainda, com base neste autor, em relação à identidade se apresentar do diálogo do interno para com o externo de cada indivíduo, a memória social/identitária de cada indivíduo apesar de ser exclusiva e específica ao mesmo, ou seja, suas apreensões acerca do real, bem como, a maneira como instituem o espaço (da mesma forma que o espaço se institui, segundo a perspectiva assumida para essa reflexão), é constituída das interrelações destes indivíduos ao longo de suas trajetórias nas mais diversas escalas. 
EM

\section{Perfil dos Catadores no Brasil segundo o IBGE/IPEA}

Conforme a Pesquisa Nacional de Amostra Domiciliar (PNAD) de 2013, 159.390 pessoas no Brasil se declararam catadores de materiais recicláveis. No estudo elaborado pelo IPEA (2013), a partir dos dados do Censo Demográfico de 2010, realizado pelo Instituto Brasileiro de Geografia e Estatística - IBGE, foi apontado que existem no Brasil 387.910 pessoas que tem na catação de materiais recicláveis sua principal atividade remunerada.

Apesar de os dados levantados pelo Censo 2010 não conseguirem captar o contingente total de pessoas que trabalham como catadores e catadoras de materiais recicláveis, o estudo elaborado pelo IPEA (2013) consegue fazer uma síntese dos principais indicadores sociais desses sujeitos da rede da reciclagem, revelando assim, o perfil socioeconômico.

Comparando a PNAD de 2013 com a PNAD de 2007 (Gráfico 1), o número de pessoas que declararam a profissão de catadores caiu $40 \%$, pois, em 2007 , foram registrados 263.528 catadores no Brasil. Vale ressaltar que, em 2013, o país tinha uma taxa de desemprego de 5\%, ou seja, tecnicamente pleno emprego e a economia e o consumo em alta atividade, aquecidos, com a emergência das classes subalternizadas, que galgaram poder de compra.

A Região que registrou a menor redução de catadores foi a região Sul, com queda de $58 \%$ do número de catadores autodeclarados.

Gráfico 1 - Número de catadores por regiões: comparação entre (2007 e 2013).

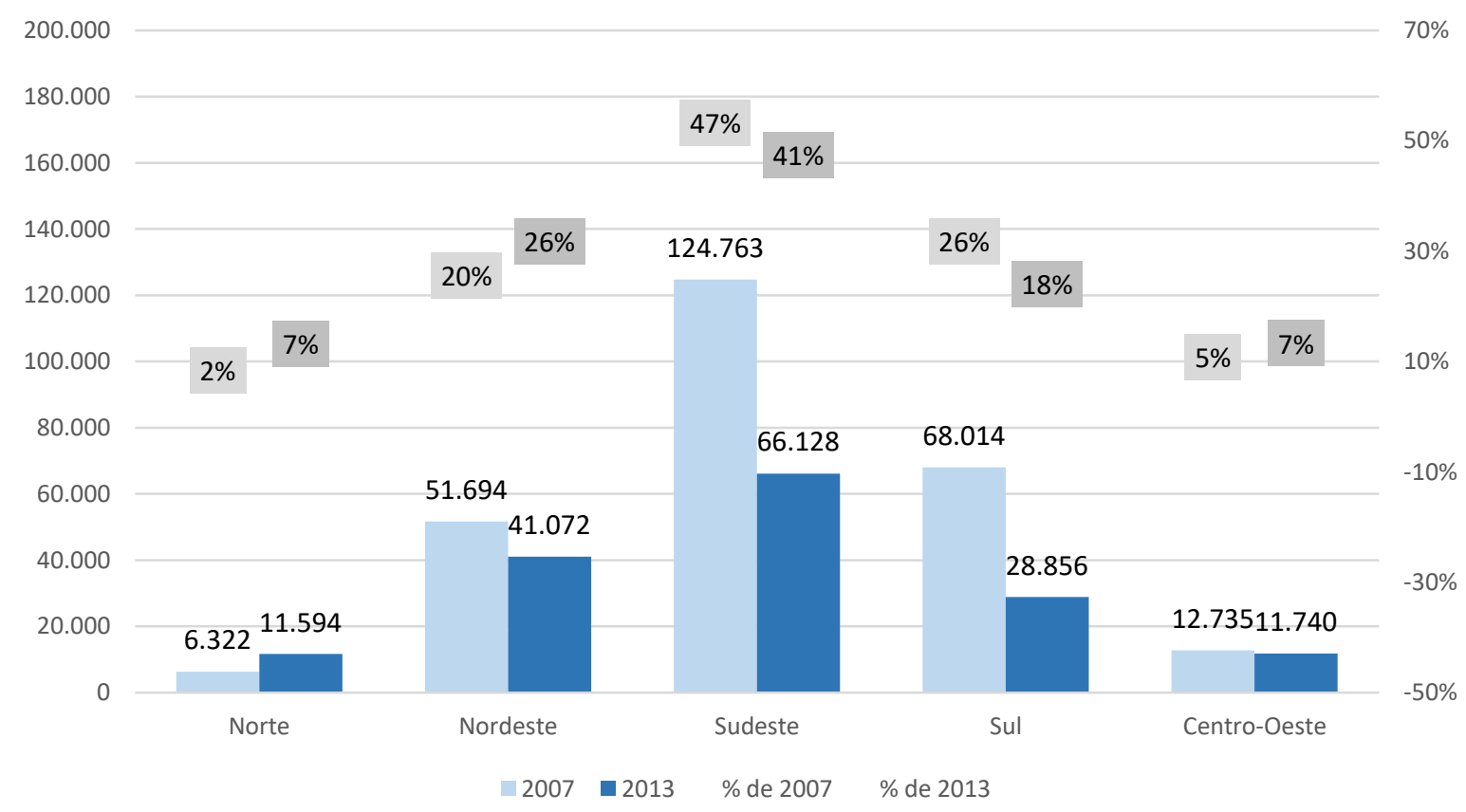

Legenda: Elaborado a partir de dados de PNAD 2007 e PNAD 2013.

Fonte: IBGE/PNAD.

\section{Rendimento médio do trabalho}

Uma dimensão essencial na análise da situação social dos catadores e catadoras de material reciclável e reutilizável no Brasil refere-se aos temas do trabalho e da renda obtida pelos trabalhadores do setor. Os dados da PNAD indicam que o rendimento médio mensal no 
EM

QUESTÃO

trabalho da catação, em 2013, segundo os próprios trabalhadores, era de $\mathrm{R} \$ 305,00$. Ressaltese que o salário mínimo da época era de $\mathrm{R} \$ 678,00$. O Nordeste apresenta situações peculiares, sendo uma delas a concentração de quantidades de materiais pelo território em menor abundância, embora, o contingente populacional expressivo, ao mesmo tempo espraiado pelo território vasto do Nordeste em relações aos demais estados do país.

A renda per capita menor e o consumo diferenciado de industrializados, optando por produtos naturais no seu cotidiano alimentar. Podemos inferir que a evolução econômica do país de 2007 a 2013 fez com que a quantidade de trabalhadores da catação decrescesse devido ao investimento público, projetos sociais, geração de trabalho e renda em setores da economia urbana e rural que absorve a mão de obra dos catadores, assim, trabalhando na construção civil, costureira, comércio de serviços em geral, agricultura, pesca, empregada doméstica.

É possível verificar experiências exitosas de renda de mais de R\$: 1.000,00 (Hum Mil Reais) mensais na CAEC, que está situada em Salvador, na Bahia. Porém, esta experiência, concomitantemente, está atrelada à venda na rede CATABahia, parcerias com a rede de supermercados Wall Mart, na prestação de serviços de coletas em suas docas, prestação de serviços em grandes eventos, tais como carnaval de Salvador, Festival de verão, dentre outros. Concluindo, o Nordeste não tem força industrial como nas regiões do Sul e Sudeste do país, que conseguem galgar taxas de rendimentos maiores. Entre as regiões, a região Nordeste apresenta o menor valor na remuneração da catação. A Região Sul é onde o rendimento médio registrou maior média ( $\mathrm{R} \$ 679,00)$. Entretanto, curiosamente, o estado onde o rendimento médio por trabalho principal do catador atingiu maior valor é o Espírito Santo, na região Sudeste (R \$ 1.119,00).

Gráfico 2 - Rendimento médio mensal por trabalho principal dos catadores - grandes regiões (2013).

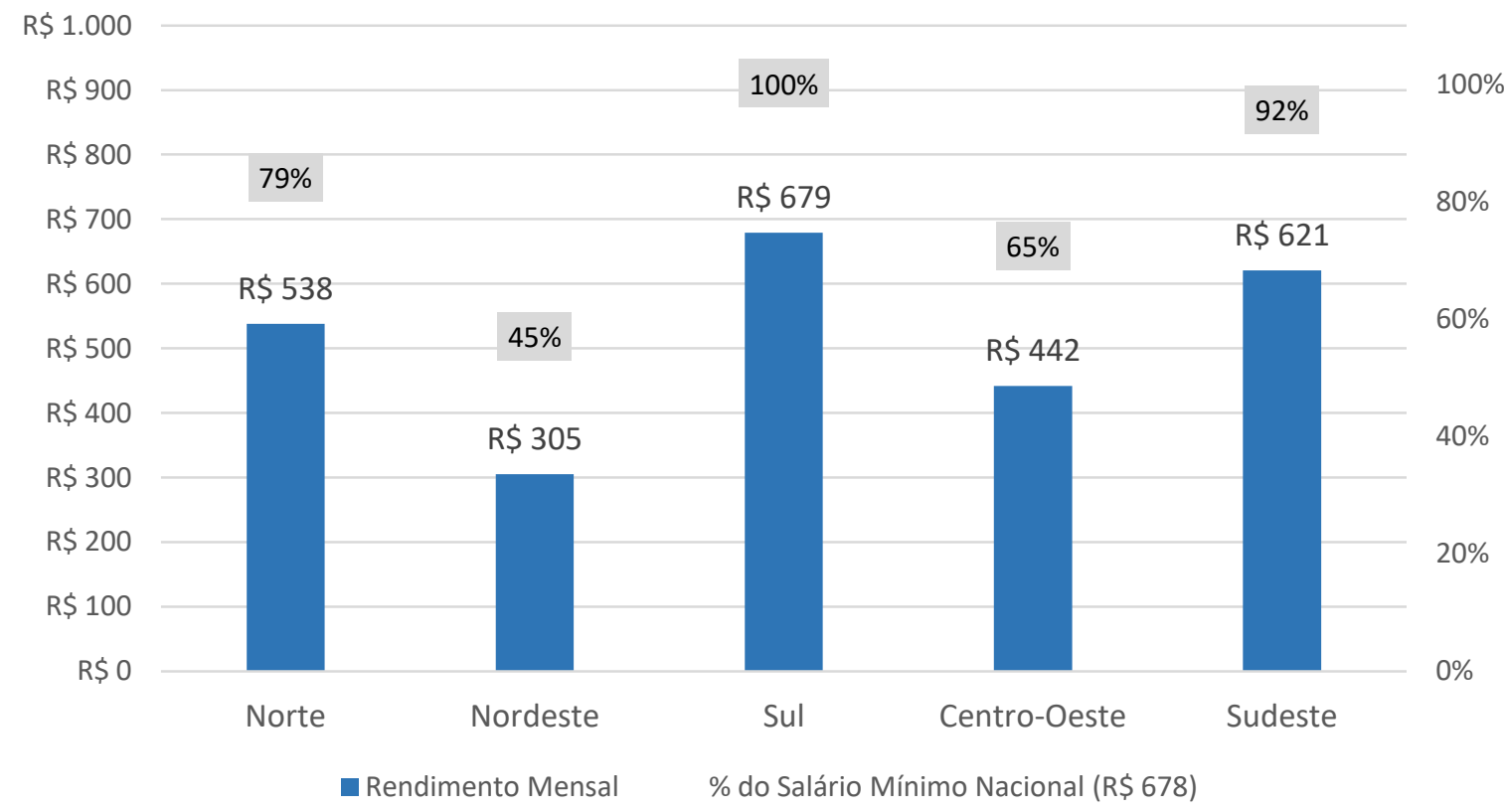

Legenda: Elaborado a partir de dados da PNAD 2013.

Fonte: IBGE/PNAD.

Os dados do Censo 2010, analisados pelo Instituto de Pesquisa Econômica Aplicada IPEA (2013), indicaram que a média do rendimento mensal dos catadores estava em $\mathrm{R} \$$ 
EM

QUESTÃO

V.13 N. $03 \bullet 2020$

pág. 98-114

571,56, valor superior ao salário mínimo da época, que era de $\mathrm{R} \$ 678,00$, segundo o Instituto de Pesquisa Econômica Aplicada - IPEA (2013).

Gráfico 3 - Rendimento médio mensal por trabalho principal dos catadores - censo (2010). $\mathrm{R} \$ 571,56$

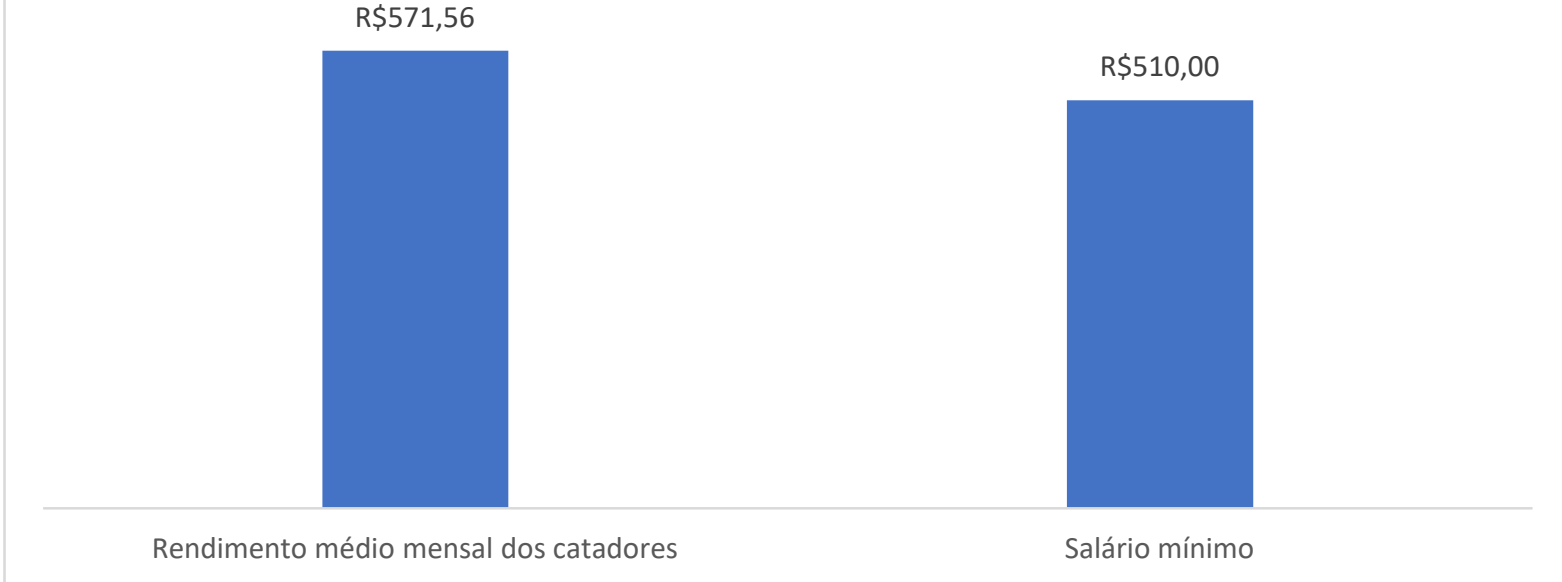

Legenda: Elaborado a partir de dados do Instituto de Pesquisa Econômica Aplicada - IPEA (2013). Fonte: IBGE/PNAD

Apontar para a distribuição de renda média, a partir das pesquisas realizadas pelo IPEA e pelo IBGE corrobora para pensarmos a respeito da situação dos catadores de materiais recicláveis no Brasil. O valor de $\mathrm{R} \$ 571,56$ se explica, especificamente, pelo acúmulo de crescimento da economia desde 2003, que Harvey (2011) chama de economia saudável e, consecutivamente, tais dados refletem a falta de seguridade social, custos trabalhistas, $\mathrm{o}$ considerável aumento de projetos para catadores, uma construção de parceiros doadores, grandes eventos nos quais os catadores foram incluídos, que resultaram nos dados acima apresentados.

Para tanto, é importante destacar que esta atividade é uma resposta ao tensionamento e à marginalização destes sujeitos, a partir de relações de poder, instituídas pelo sistema capitalista, sobretudo em um país periférico, tal como o Brasil. Segundo Harvey (2011), o sistema capitalista responde a uma lógica de acúmulo de capital constante, sempre em um processo de geração de lucro para determinada classe em detrimento de outra classe. Deste modo, o autor afirma haver a classe exploradora, cujo capitalista está inserido enquanto proprietário de recurso financeiro e, destarte, localizado na centralidade das relações de poder econômico em relação aos outros sujeitos que compõem a relação enquanto marginais. Concomitante a esta posição central do capitalista, está a posição daqueles que não detém capital e, por suposto, meios de produção, como crédito financeiro.

Para que então haja acúmulo de capital constante/permanente da classe capitalista é necessária a exploração da classe trabalhadora que detém força de trabalho e que corrobora para a geração de lucro do capitalista. Há assim uma relação retroalimentada a partir da necessidade de trabalho e capital para sobrevivência, enquanto há uma necessidade do capitalista de permanecer hierarquicamente acima nas relações econômicas de poder.

Deste modo, os catadores de material reciclável correspondem à força de trabalho a ser explorada, sem a regulação de parâmetros contidos na legislação trabalhista do país. Estes sujeitos que, como demonstrado anteriormente, constituem-se sobretudo de população negra, de mulheres e moradores de periferia pobre, justamente se colocam na condição de catadores, alimentando o ciclo da acumulação de capital discutido por Harvey (2011). Porém, paradoxalmente, estabelecem-se de trabalhadores, cujo ato de resistência à exclusão de outros setores trabalhistas presentes nas cidades é justamente o ato de catação. 
EM

QUESTÃO

V.13 N. $03 \bullet 2020$

pág. 98-114

Grau de instrução e analfabetismo - Censo 2010

Quando observamos os indicadores relativos à educação, vemos que a baixíssima escolaridade destes sujeitos da reciclagem é uma dura realidade, com taxa de analfabetismo entre catadores chegando a $20 \%$ no Brasil (sendo que a taxa geral nacional apontada pelo Censo 2010 ficou em 9,4\%). Ou seja, trata-se de mão de obra não especializada, com pouco ou nenhum acesso à educação básica pública, empurrados para as atividades marginalizadas da sociedade.

Gráfico 4 - Taxa de analfabetismo entre os catadores.

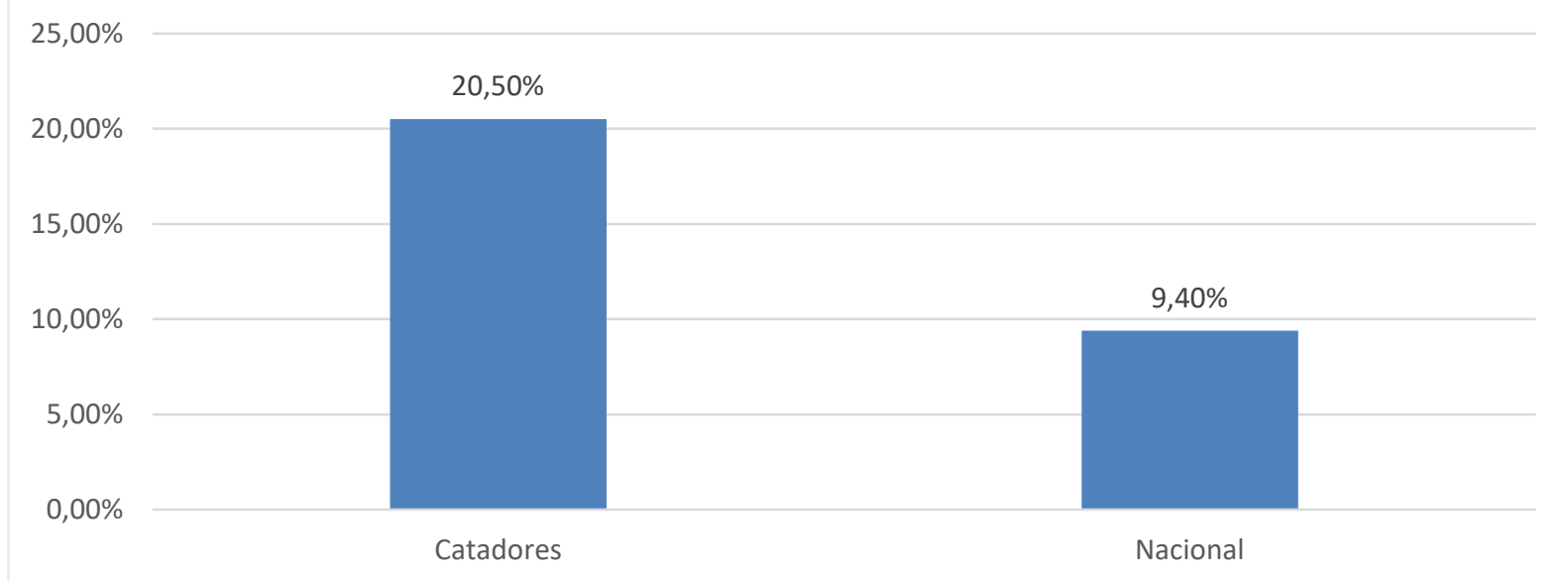

Legenda: Elaborado a partir de dados do Instituto de Pesquisa Econômica Aplicada - IPEA (2013).

Fonte: IBGE/PNAD.

No que diz respeito à escolaridade, apenas $24 \%$ dos catadores (as), no Brasil acima de 25 anos, possuem ensino fundamental completo. Cabe ressaltar que a média geral nacional foi de $50 \%$ de pessoas com o ensino fundamental completo. Mais uma vez encontramos taxas mais que o dobro de excluídos socialmente, em comparação ao quantitativo da população em geral.

Gráfico 5 - Percentual de catadores com 25 anos ou mais com ao menos o ensino fundamental completo.

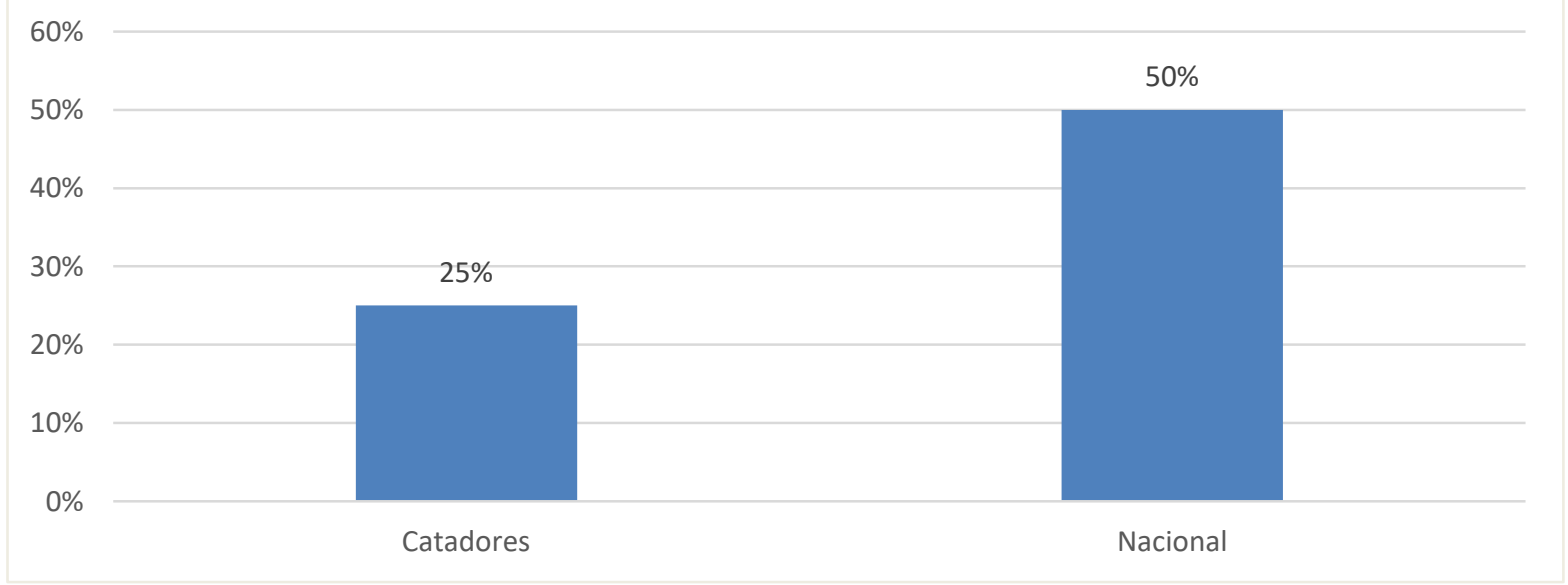

Legenda: Elaborado a partir de dados do Instituto de Pesquisa Econômica Aplicada - IPEA (2013).

Fonte: IBGE/PNAD 
EM

Ao observar a mesma faixa etária anterior, o cenário é ainda pior: daqueles que possuem o Ensino Médio completo, a média geral nacional ficou em aproximadamente 36\%, já o percentual entre os catadores cai para $11 \%$, no Brasil.

Gráfico 6 - Percentual de catadores com 25 anos ou mais com ao menos o ensino médio completo.

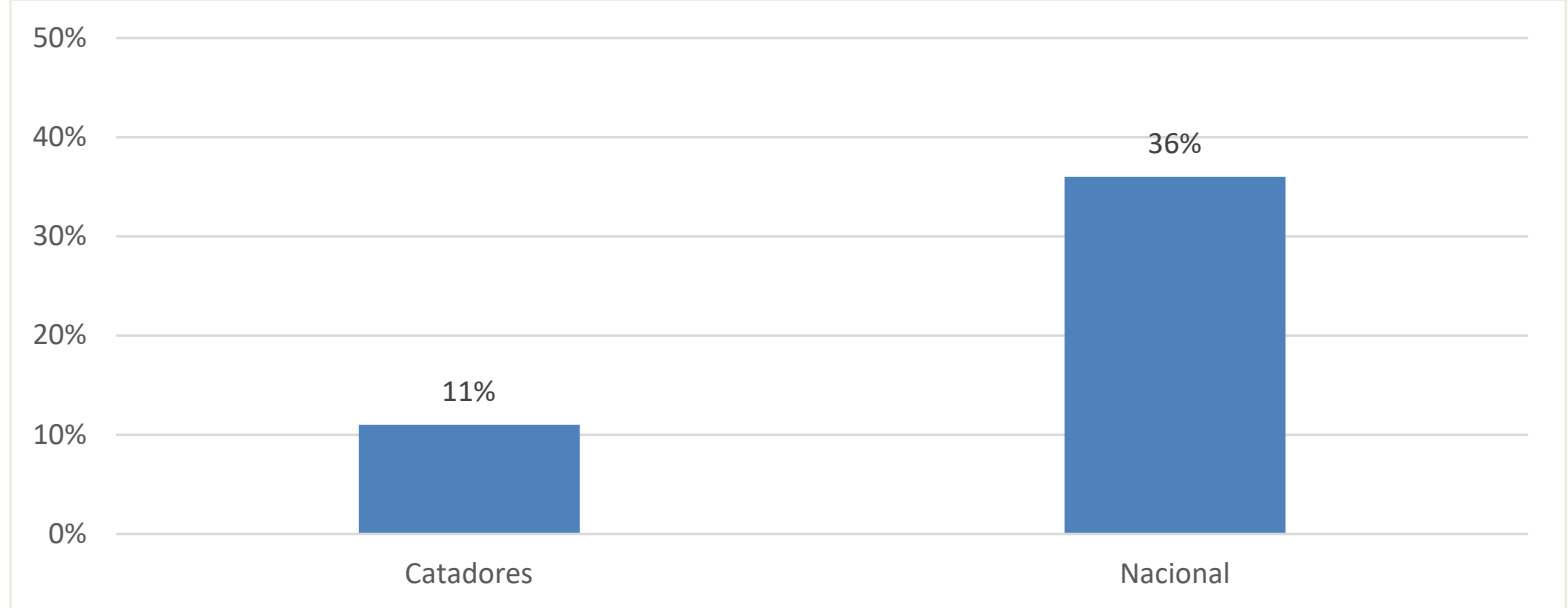

Legenda: Elaborado a partir de dados do Instituto de Pesquisa Econômica Aplicada - IPEA (2013).

Fonte: IBGE/PNAD.

\section{Participação dos catadores negros - Censo 2010}

Podemos observar também que a rede da reciclagem reflete o processo histórico de exploração e marginalização da população negra brasileira. Conforme pode se observar no Gráfico a seguir, a maioria dos catadores (as) do Brasil (66\%) são negros.

Gráfico 7 - Percentual de catadores negros (pretos e pardos).

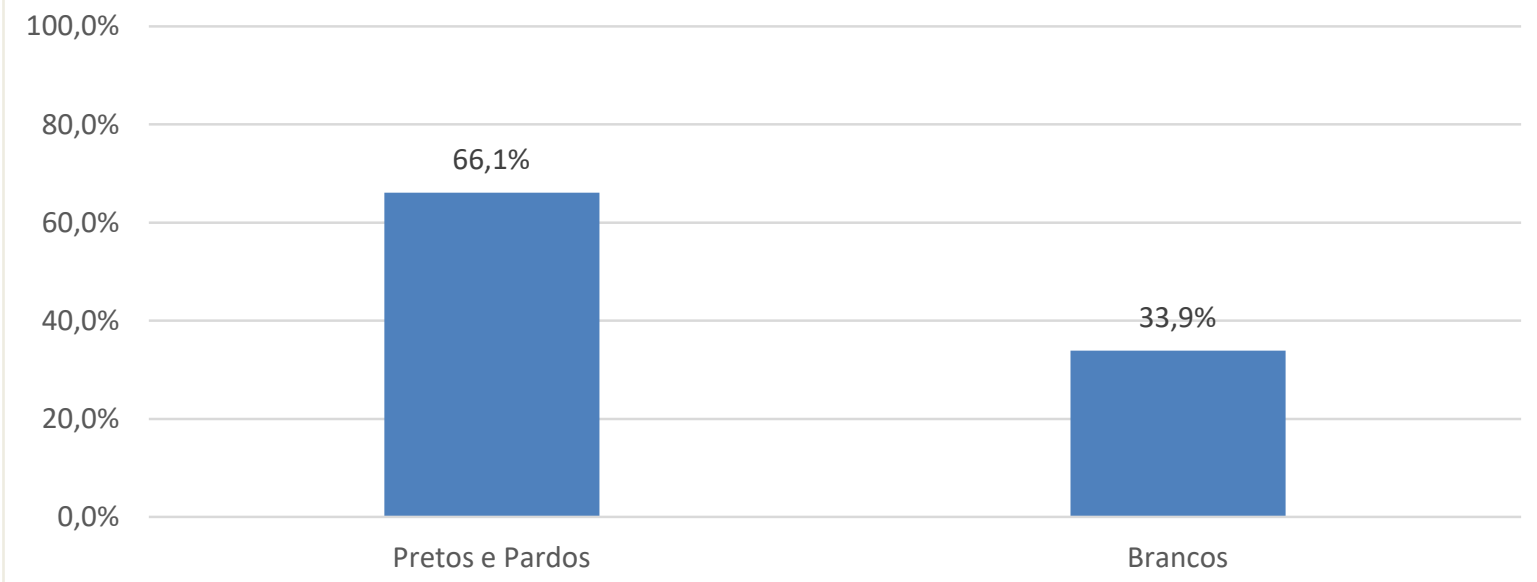

Legenda: Elaborado a partir de dados do Instituto de Pesquisa Econômica Aplicada - IPEA (2013).

Fonte: IBGE/PNAD.

Um ponto importante sobre este aspecto caracteriza-se pelo fato de que a população brasileira é majoritariamente negra (54,9\% - pretos e pardos - de acordo com a PNAD 2016). Isso significa que, em consonância com o que foi apresentado anteriormente em diálogo com Harvey (2011), embora a maioria populacional brasileira se concentre a partir desta faceta, é 
EM

QUESTÃO

V.13 N. $03 \bullet 2020$

pág. 98-114

enormemente desigual a situação entre aqueles que correspondem à classe exploradora e aqueles que correspondem à classe explorada (trabalhadora), sendo então materializada, através destes números apontados, a condição de extrema desigualdade que assola o país historicamente.

Como a atividade de coleta e reciclagem de resíduos sólidos depende do descarte de material reutilizável e reciclável, os dados do Censo Demográfico mostram que, majoritariamente, os catadores residem em áreas urbanas, pois estas são concentradoras de população, gerando, assim, mais lixo. Portanto, o lixo é, essencialmente, um problema urbano. Esse percentual em todo o país chega a 93,3\%, logo a atividade de coleta de material reciclável possui uma natureza essencialmente urbana.

O espaço é produto e produtor das relações sociais, elemento fundamental para a manutenção destas mesmas relações, conforme argumenta Corrêa (2000). Deste modo, o espaço urbano das cidades, a partir desta compreensão, é constituído a partir das relações sociais correspondentes à configuração urbana, bem como tais relações correspondem à lógica urbana.

Isto significa que a prática de reciclagem de materiais está relacionada à necessidade de a indústria obter ampliação de lucro, seja através da força de trabalho dos catadores e outros profissionais envolvidos neste segmento, seja através dos baixos custos dos materiais que servirão de matéria prima para a fabricação de mercadorias. Sendo assim, a existência de catadores de materiais recicláveis é intrínseca ao espaço urbano das cidades, em decorrência da distribuição das indústrias, além da ampla disponibilidade de rejeitos sólidos relacionado ao inchaço populacional das cidades.

Segundo o Censo 2010, os dados acerca do percentual de catadores (as) que se encontram residindo em áreas urbanas corrobora com a análise de Damásio (2011), que aponta a ligação existente entre a problemática dos resíduos sólidos e o processo de esvaziamento das zonas rurais e o consequente inchamento das cidades. Como já mencionado nesta pesquisa, os centros urbanos são concentradores populacionais, gerando, assim, maior quantidade de lixo. Ou seja, o lixo é um problema das áreas urbanas e não rurais. Os dados do Censo 2010 apontaram que no Brasil, 93\% desses trabalhadores estão no meio urbano.

Gráfico 8 - Percentual de catadores residentes em áreas urbanas.

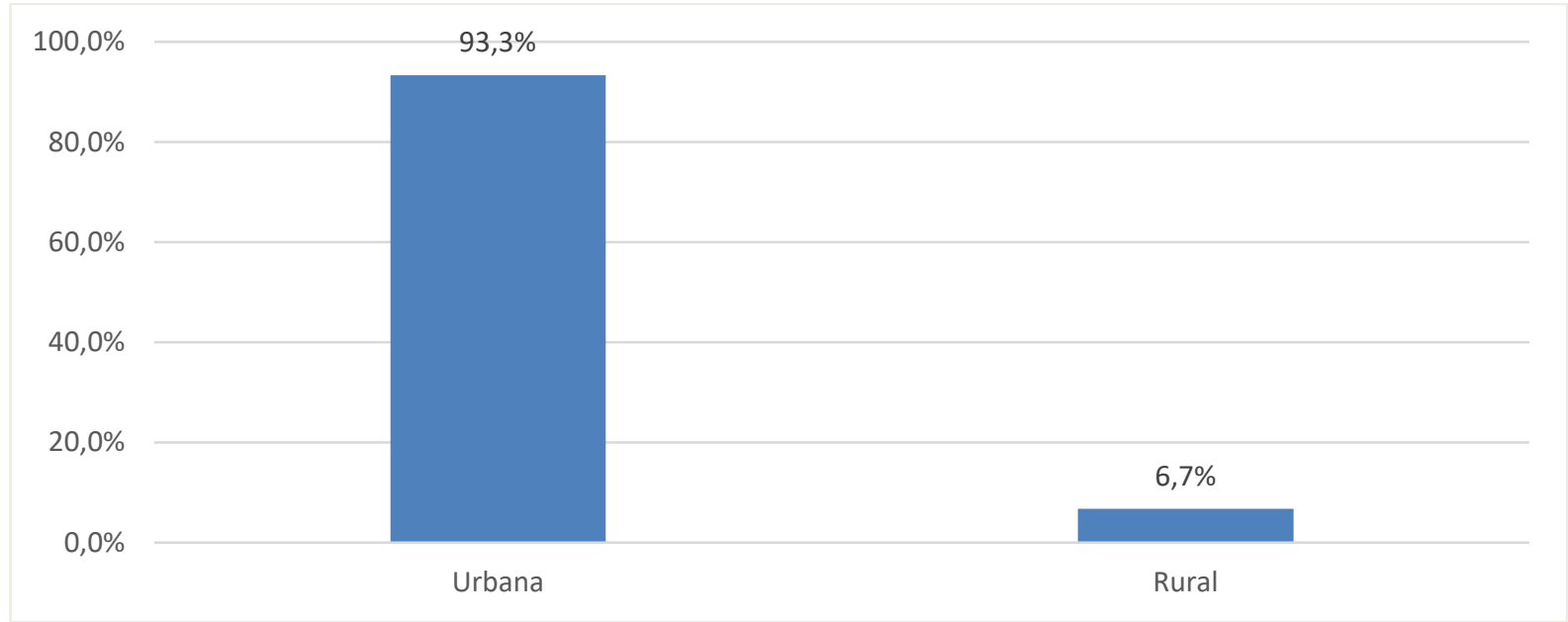

Legenda: Elaborado a partir de dados do Instituto de Pesquisa Econômica Aplicada - IPEA (2013). Fonte: IBGE/PNAD.

De acordo com os estudos de Milton Santos, o circuito superior seria então definido pela lógica direta do capital, conduzido para manter posição da camada social que controla os 
EM

QUESTÃO

V.13 N. $03 \bullet 2020$

pág. 98-114

meios de produção, enquanto o circuito inferior seria composto por indivíduos marginalizados no sistema capitalista de produção, como é o caso dos negros escravizados historicamente e que continuam, ainda hoje, sendo empurrados para as camadas menos privilegiadas da sociedade, necessitando de estratégias para transpor as barreiras sociais e legais de exclusão impostas pelos sujeitos controladores do primeiro circuito.

\section{Conclusão}

A geografia, de forma geral, é um estudo que pretende compreender os espaços geográficos, contudo, seu viés social, busca desvelar a relação dos indivíduos com esses espaços e todas as suas nuances, estabelecendo as multiplicidades de construções possíveis estabelecidas por essa relação.

Neste trabalho, foi possível compreender o espaço como construto social, ou seja, fruto das relações entre os indivíduos que o ocupam, em um processo de constante construção de identidades. O espaço depende das relações sociais, assim como as relações sociais necessitam do espaço, são ambos interdependentes.

Assim, o objetivo desse trabalho foi refletir sobre o espaço, os sujeitos sociais e as redes relacionados ao âmbito da reciclagem brasileira, lembrando que essa atividade exploratória e marginalizada é uma demanda particular do modo de produção capitalista que, por si só, gera uma grande quantidade de resíduos sólidos.

Resumidamente, este artigo se debruçou sobre as relações de poder que existem na atividade de reciclagem e da catação, observando o espaço e a construção da identidade dos sujeitos que compõem a rede de produção da reciclagem em questão e traçando um perfil mais detalhado quantitativamente dos mesmos.

Concluiu-se, a partir dos dados quantitativos, que corroboram com o que foi discutido neste trabalho, que os trabalhadores da atividade da reciclagem continuam ocupando uma posição de marginalização na sociedade com poucas chances de ascensão devido a diversos fatores como: a baixa remuneração, baixa escolarização, sendo que a maioria não concluiu o ensino básico, idades avançadas, grande parte são idosos, vulnerabilidade social, idosos que não possuem benefício previdenciário, dentre outros.

Por fim, cabe dizer que a discussão deste artigo procurou refletir sobre a importância de se analisar as relações de trabalho e exploração dos trabalhadores da coleta seletiva, colaborando, assim, para um entendimento melhor da organização desigual do espaço, já que é mantida uma lógica de exclusão destes trabalhadores no espaço, a partir das relações de trabalho e da posição social na qual se inserem.

Certamente, esta revisão não pretende ser a única a tratar dessa temática. Pelo contrário, representa um tema que ainda está emergente na Geografia, podendo contribuir para essa compressão das relações sociais e de trabalho no Brasil. Além disso, é importante colocar em evidência, através de estudos acadêmicos, uma necessidade de se olhar para os indivíduos excluídos e invisíveis da sociedade brasileira, revelando e compreendendo todo o sistema que causa essas opressões e lutando para que um dia existam relações de trabalho mais equilibradas e benéficas para todos.

\section{Referências}

BAUMAN, Zygmunt. Identidade: Entrevista a Benedetto Vecchi. Trad.: Carlos Medeiros. Rio de Janeiro: Zahar, 2005. 110 p. 
EM

BOSI, A. P. A organização capitalista do trabalho "informal": O caso dos Catadores de Recicláveis. Revista Brasileira de Ciências Sociais. Brasil, v. 23, n. 67, p. 101-116, 2008.

BURGOS, R. Periferias Urbanas da Metrópole de São Paulo: Territórios da base da indústria da reciclagem urbana periférica. 357f. Tese (Doutorado em Geografia) Departamento de Geografia, Universidade de São Paulo, São Paulo, 2008.

CORREAA, Roberto Lobato. Espaço, um conceito-chave da Geografia. In: Geografia: Conceitos e Temas. CASTRO, I. E.; GOMES, P. C. C.; CORREA, R. L. (Org.). Rio de Janeiro: Bertrand Brasil, 2000.

COSTA, W. B.; CHAVES, M. R. Informalidade e Precarização do Trabalho de Catação de Materiais Recicláveis no Brasil: Pontos para debate. In: XIII Jornada do Trabalho. 2012, Presidente Prudente. Anais da XIII Jornada do Trabalho. Presidente Prudente: CEREST, 2012. 12).

DAGNINO, R. S.; DAGNINO, R. P. Políticas para Inclusão Social dos Catadores de Materiais Recicláveis. Revista Pegada Especial, p. 65-93, 2010.

FOUCAULT, M. Sujeito e Poder. In: DREYFUS, H.; RABINOW, P. Michel Foucault, uma trajetória filosófica: (para além do estruturalismo e da hermenêutica). Rio de Janeiro: Universitária, 1995.

GOLDENBERG, M. A arte de pesquisar: como fazer pesquisa qualitativa em ciências sociais. $8^{\text {a }}$ ed. - Rio de Janeiro: Record, 2004.

GONÇALVES, M. A. O Trabalho no Lixo. 2006. 310 f. Tese (Doutorado em Geografia). Departamento de Geografia. Universidade Estadual Paulista "Júlio de Mesquita Filho", Presidente Prudente, 2006.

HALL, Stuart. A identidade cultural na pós-modernidade. Rio de Janeiro: DP\&A, $11^{\text {a }}$ Ed., 2011, $102 \mathrm{p}$.

HARVEY, D. O enigma do capital: e as crises do capitalismo. São Paulo: Boitempo, 2011.

IBGE. Pesquisa nacional por amostra de domicílios. Disponível em: <https://ww2.ibge.gov.br/home/estatistica/pesquisas/pesquisa_resultados.php?id_pesquisa=40 >. Acesso em: 10 jun. 2018.

LACOSTE, Y. A pesquisa e o trabalho de campo: um problema político para os pesquisadores, estudantes e cidadãos. Boletim Paulista de Geografia. Brasil, v. 84, p. 77-92, 2006.

LUSSARI, W. R. Grupo de Apoiadores e Cooperlix em Presidente Prudente - SP, Brasil. Modelo e Evolução de suas Relações durante Quinze Anos. 2016. 276 f. Tese (Doutorado em Geografia) - Departamento de Geografia. Universidade Estadual Paulista "Júlio de Mesquita Filho", Presidente Prudente. 2016. 
EM

MASSEY, Doreen B. Pelo Espaço: Uma nova Política da Espacialidade. Rio de Janeiro: Bertrand Brasil, 2008, 312 p.

MEDINA, M. The World's Scavenger: Salvage for Sustainable Consumption and Production. Lanham. MD: AltaMira Press, 2007.

MINAYO, M. C. S. Ciência, técnica e arte: o desafio da pesquisa social. In: MINAYO, M. C. S. (Org.). Pesquisa social: teoria, método e criatividade. Petrópolis, RJ: Vozes, 2001.

POLLACK, Michael. Memória e Identidade Social. Rio de Janeiro: Estudos Históricos, v. 5, n. 10,1992 , p. $200-212$.

PORTO-GONÇALVES, C. W. A Globalização da Natureza e a Natureza da Globalização. Rio de Janeiro: Civilização Brasileira, 2006.

RAFFESTIN, C. Por uma Geografia do Poder. São Paulo: Ática, 1993.

ROSADO, R. M. Na Esteira do Galpão: Catando leituras no território cotidiano da reciclagem do lixo de Porto Alegre/RS. 2009. 333 f. Tese. (Doutorado em Geografia) Departamento de Geografia. Universidade Federal do Rio Grande do Sul, Porto Alegre, 2009.

SANTOS, B. S. A construção multicultural da igualdade e da diferença. In: Congresso Brasileiro de Sociologia, 1995. Rio de Janeiro. Anais do Congresso Brasileiro de Sociologia. 1995.

SANTOS, Milton. O Espaço Dividido: os dois circuitos da economia urbana dos países subdesenvolvidos. $2^{\circ}$ ed. São Paulo: Edusp, 2008.

SILVA, M. C. P. O Trabalho dos Catadores de Materiais Recicláveis de Uberaba - MG e a Relação com os Dois Circuitos Econômicos da Reciclagem. Revista Pegada, v. 18, n. 03, 2017.

SOUZA, Marcelo Lopes de. Os conceitos fundamentais da pesquisa sócio-espacial. Rio de Janeiro: Bertrand Brasil, 2013. 320 p. 